\title{
Continuidade de Políticas Públicas: A Constitucionalização Importa?
}

Cláudio Gonçalves Couto

Giovanna de Moura Rocha Lima ${ }^{1}$

1. Fundação Getulio Vargas (FGV), São Paulo, SP, Brasil. E-mail para contato: claudio.couto@fgv.br.

\section{INTRODUÇÃO}

onstituições estabelecem as regras do jogo político e os limiares e

limites da legalidade maior das decisões resultantes de tal jogo. As definições do Estado e as regulações sobre a interação política, conteúdo por excelência das cartas magnas, são estruturais para as políticas públicas: diferentes escolhas institucionais alteram as estruturas de decisão, incentivo e responsabilização sobre sua formulação e implementação.

As constituições também impõem limites substantivos às ações dos governos, especialmente por meio da constitucionalização de direitos. Entendemos por constitucionalização a inserção explícita de matérias no texto constitucional. Uma vez constitucionalizada, a matéria torna-se vinculante para o legislador ordinário, em contraste com as matérias não constitucionalizadas, deixadas à discricionariedade legislativa.

Uma noção distinta de constitucionalização é empregada pelas abordagens neoconstitucionalistas mais influentes (Zagrebelsky, 1995; Carbonell, 2010; Barroso, 2005). Nelas a constitucionalização é considerada um fenômeno que transcende a mera inserção no texto, associando-se "a um efeito expansivo das normas constitucionais, cujo conteúdo material e axiológico se irradia, com força normativa, por

DADOS - Revista de Ciências Sociais, Rio de Janeiro, vol. 59, no-4, 2016, pp. 1055 a 1089. 
todo o sistema jurídico" (Barroso, 2005:12)로. Ademais, é possível entendê-la também como um processo genérico de "constitucionalização do direito", baseado não apenas na irradiação do que está previsto no texto constitucional, como também na aplicação de princípios mais abrangentes ao controle de constitucionalidade, cobrindo lacunas jurídicas não só da normatividade infraconstitucional, mas do próprio texto da Constituição (Zagrebelsky, 1995; Nuñes Leiva, 2012). Isto acontece em decorrência da atribuição de força normativa à $\mathrm{Carta}^{2} \mathrm{e}$ da centralidade da Constituição no sistema jurídico ${ }^{3}$ (Barcellos, 2005; Barroso, 2005; Cambi, 2007) .

É importante notar que mesmo dentro da corrente neoconstitucionalista há perspectivas concorrentes. Ana Paula de Barcellos (2005:91), por exemplo, defende que o texto constitucional especifique políticas públicas para garantir direitos, asseverando que:

(i) a Constituição estabelece como um de seus fins essenciais a promoção de direitos fundamentais; (ii) as políticas públicas constituem o meio pelo qual os fins constitucionais podem ser realizados de forma sistemática e abrangente; (iii) as políticas públicas envolvem gasto de dinheiro público; (iv) os recursos públicos são limitados e é preciso fazer escolhas; $\log o$ (v) a Constituição vincula as escolhas em matéria de políticas públicas e dispêndio de recursos públicos.

Já Luis Roberto Barroso (2005:20), referindo-se à Constituição brasileira de 1988, nota excessos na orientação defendida por Barcellos:

A euforia constituinte - saudável e inevitável após tantos anos de exclusão da sociedade civil - levou a uma Carta que, mais do que analítica, é prolixa e corporativa. (...) todos os principais ramos do direito infraconstitucional tiveram aspectos seus, de maior ou menor relevância, tratados na Constituição. A catalogação dessas previsões vai dos princípios gerais às regras miúdas, levando o leitor do espanto ao fastio. (...) Trata-se da constitucionalização das fontes do Direito naquela matéria. Tal circunstância, nem sempre desejável, interfere com os limites de atuação do legislador ordinário e com a leitura constitucional a ser empreendida pelo Judiciário em relação ao tema que foi constitucionalizado.

O fato é que, de uma forma ou de outra, as constituições contemporâneas incidem cada vez mais sobre as ações dos governos, frequentemente demandando ou restringindo a formulação de políticas públicas, influenciando diretamente os produtos do jogo político. A 
constitucionalização do direito à educação, por exemplo, exigirá que governos se empenhem para garanti-lo. Este processo demanda a mobilização de diferentes atores, tendo em vista que as políticas públicas específicas a serem adotadas passam a constituir objeto de disputa. A constitucionalização de conteúdos substantivos (políticas públicas propriamente, não apenas princípios ou regras procedimentais) abre possibilidades, fornece ferramentas e representa um ponto focal para a organização dos atores sociais ao interpelar governos ${ }^{5}$. É esperado que diferentes governos atuem de forma a priorizar alguns direitos mais do que outros, dando primazia a políticas que lhes deem efetividade e esta é sua prerrogativa.

Por outro lado, havendo o controle de constitucionalidade, a ausência do reconhecimento explícito de um direito na constituição pode dar pretexto para atores sociais e político-institucionais acionarem o Judiciário contra o encaminhamento de determinadas políticas às quais se oponham por razões várias. Entretanto, mesmo que ausentes formalmente do texto da Constituição, certos direitos podem ser assegurados com base em princípios. Esta possibilidade torna ainda mais intrigante a constitucionalização de políticas públicas. Afinal, se direitos podem ser garantidos constitucionalmente mesmo quando não inscritos formalmente no texto, para que então constitucionalizar políticas que têm por fim lhes dar efetividade? Note-se bem, referimo-nos aqui a políticas que se tornam formalmente constitucionais ao serem inseridas no texto da Constituição, mesmo que não sejam materialmente constitucionais (Zagrebelsky, 1995:114-115) ${ }^{6}$.

Quais as consequências de uma constituição incorporar em seu texto matérias usualmente sujeitas ao desenrolar do jogo político, especificando não só princípios, direitos, ou procedimentos gerais deste jogo, mas descendo aos detalhes das políticas públicas? Ora, ao inserirem políticas públicas numa constituição, os atores visam não apenas assegurar que - na falta de magistrados neoconstitucionalistas - certos direitos sejam formalmente resguardados pela positivação das políticas públicas que lhes dão efetividade, mas também fazer valer seus interesses econômicos ou preferências políticas.

A contribuição que este artigo visa proporcionar é fundamentalmente teórica: a elaboração de um modelo analítico que possibilite, com a realização de posteriores estudos empíricos, responder à pergunta: a constitucionalização de políticas públicas afeta sua continuidade de 
forma determinante? Ou seja, a inserção de políticas públicas no texto constitucional faz com que elas sejam mantidas por mais tempo? Formulamos ainda hipóteses sobre mecanismos que funcionam na garantia da continuidade de matérias formalmente constitucionais e se características das diferentes políticas e constituições impactam esta dinâmica.

Não identificamos na literatura de ciência política, apesar da vasta produção na área, análise sobre a dinâmica das políticas públicas constitucionalizadas. Estudos como os de Christopher W. Hammons (1999; 2001), Donald Lutz (1994; 2006), Astrid Lorenz (2005) e Gabriel Negretto (2008) tratam de constituição, emendamento constitucional e mudança constitucional, mas não consideram a relação entre políticas públicas e constituição da forma como fazemos neste artigo. De fato, a constituição tomada em si mesma como objeto de estudo da ciência política é uma realidade recente e em desenvolvimento, em particular na produção acadêmica latino-americana e sobre a América Latina. Por isso, conciliamos a literatura de constitucionalismo da ciência política com a literatura de políticas públicas, formulando um modelo voltado ao entendimento da forma pela qual a constitucionalização das políticas eventualmente altera sua dinâmica.

Além desta introdução, o artigo conta com a seção de revisão de literatura, na qual apresentamos as dinâmicas da constituição e das políticas públicas. A seção seguinte trata das políticas públicas já constitucionalizadas e sugere um modelo de análise sobre sua continuidade. A última seção conclui o texto e apresenta caminhos para futuros estudos. Argumentamos que a constitucionalização é determinante para políticas que não têm fontes de resiliência que assegurem seu autorreforço e cujos opositores não têm capacidade de mobilizar uma maioria de atores político-institucionais suficientemente ampla para superar os custos do processo de modificação constitucional.

\section{REVISÃO DE LITERATURA}

\section{Dinâmica Constitucional}

Historicamente, tornou-se cada vez mais comum a sistematização de constituições em um documento escrito ${ }^{7}$. A existência de tal tecnologia no mundo moderno pode ser datada de 1787, ano da Convenção da Filadélfia, cujo resultado foi a Constituição dos Estados Unidos da América, ou mesmo antes, se considerarmos as constituições já adotadas 
por estados membros até então. As constituições escritas não encerram em si o ordenamento constitucional de um país: alguns aspectos da vida política que tendemos a pensar como fundamentais por vezes não são por elas regulados (Elster, 1995:367). Ainda assim, cartas magnas constituem a melhor representação da ordem constitucional (Elkins, Ginsburg e Melton, 2009:loc.899), e são fundamentais para a proteção de direitos e a obstaculização a certas mudanças políticas (Elster, 1988:3).

As escolhas institucionais substantivas consolidadas em uma constituição são parcialmente explicadas pelo seu processo de elaboração. A negociação política entre os autores do texto constitucional já começa na definição das regras organizacionais que balizarão o processo constituinte (Gomes, 2006:195). Políticos têm suas próprias ideias e preconceitos (Elster, 1995; Horowitz, 2002) e há evidência de que assembleias constituintes são dominadas pelo interesse de curto prazo dos políticos em vez dos interesses de longo prazo dos cidadãos (Ginsburg, 2003:23). É correto antecipar, por exemplo, a constitucionalização de "interesses particulares inegociáveis, sem cuja garantia o convívio pacífico e a competição política leal entre os diversos setores sociais e políticos seriam inviabilizados" (Couto e Arantes, 2006:48). Para além destes, é de se esperar que grupos de interesse busquem colocar suas escolhas políticas na constituição, tornando-as mais detalhadas (Elkins, Ginsburg e Melton, 2009: loc.1921).

O processo constituinte envolve escolhas coletivas (Elster, 1995:365). Assim, "o resultado final não pode ser explicado somente com base nas preferências individuais iniciais dos atores políticos" (Gomes, 2006:194). Devemos considerar concomitantemente os constrangimentos institucionais, as metas dos constituintes e os mecanismos pelos quais essas metas são agregadas em escolhas coletivas. Os pressupostos e crenças dos constituintes formam a ponte entre suas metas e suas preferências por determinadas disposições constitucionais (Elster, 1995:365).

O reconhecimento da relevância das regras e dos atores participantes do processo constituinte para os outcomes constitucionais deve estar aliado a considerações acerca da situação histórica e política do país. O escopo e o alcance da constituição dependerão bastante do contexto. Como argumentam Zachary Elkins, Tom Ginsburg e James Melton, "demandas de constitucionalização de qualquer tópico dependerão 
do tempo e do lugar específico em que a constituição está sendo escrita" (2009:loc.1900, tradução livre) $)^{8}$.

O fundamental para garantir a sobrevivência da constituição é que o texto elaborado seja autovinculante (self-enforcing ou self-binding) ${ }^{9}$, isto é, que ela faça sentido para aqueles que vivem sob seus ditames e que os atores políticos relevantes não atuem contra ela. Ainda que barganhas constitucionais tenham ganhadores e perdedores relativos, elas vão perdurar enquanto as partes acreditarem que mais se beneficiam dos processos de negociação já estabelecidos do que de uma alternativa em cuja busca tenham que se arriscar e investir recursos (Elkins, Ginsburg e Melton, 2009:loc.233). Assim, constituições são barreiras de papel (parchment barriers) na medida em que são os atores políticos relevantes que agem para sua manutenção: são eles que as sustentam. Portanto, "quaisquer circunstâncias específicas que deram vida à constituição, as regras e princípios que anuncia precisam encontrar base social para sustentar-se" (Comella, 2009:30, tradução livre). A capacidade mobilizadora da constituição em sua própria manutenção e implementação é acompanhada da necessidade de mudanças que permitam sua atualização.

Como argumenta Lutz, "todas as constituições requerem modificações regulares, periódicas, seja por emendamento, alteração judicial ou legislativa, ou substituição" (1994:357, tradução livre). É de se esperar, portanto, que diferentes partes do texto sofram alterações pontuais, apesar de a constituição como um todo gerar um processo de selfbinding e ser relativamente estável por conta dos custos de recoordenação e da defesa dos atores políticos que a sustentam. Mudanças do texto constitucional são, em princípio, reflexos das mudanças pelas quais passa o regime político, que por sua vez é influenciado por mudanças no ambiente em que o sistema opera (incluindo economia, tecnologia, relações internacionais, demografia etc.); mudanças no sistema de valores esposado pela população; efeitos institucionais indesejados ou inesperados; e pelo efeito cumulativo das decisões tomadas pelos poderes legislativo, executivo e judiciário (Lutz, 1994). A sobrevivência de uma instituição, de fato, frequentemente depende do seu grau de flexibilidade e adaptabilidade:

Assim, constituições frequentemente evoluem por um processo de estratificação [layering] que preserva grande parte de seu cerne enquanto adiciona emendas por meio das quais regras e estruturas herdadas do 
passado podem ser postas em sintonia com as mudanças nos ambientes normativo, social, e político (Thelen, 2003:228, tradução livre).

Os dois principais mecanismos de mudança constitucional são os emendamentos formais ao texto ${ }^{10} \mathrm{e}$ as mudanças interpretativas tipicamente facilitadas pelas cortes (Elkins; Ginsburg; Melton, 2009:loc.1659). Tais instrumentos refletem a atuação do Legislativo e do Judiciário, respectivamente, na mudança constitucional.

De acordo com diferentes suposições e metas em mente, constituintes desenvolveram diversos métodos formais de emendamento constitucional. Tais métodos são associados ao grau de rigidez constitucional ${ }^{11}$, e afetam os custos que incidem sobre os atores que buscam alterar o texto. O processo pode variar principalmente quanto a quem tem direito de iniciar o emendamento, ao processo de aprovação das emendas, às áreas do texto sujeitas à modificação, à participação popular e se o trabalho legislativo está sujeito ao controle de constitucionalidade exercido pelo judiciário. Lutz (1994:368) identifica 30 possíveis formas pelas quais o processo de emendamento pode ter início, e outras 38 alternativas de procedimentos para aprovação ${ }^{12}$. Diferentes aspectos do ordenamento político são refletidos no processo de emendamento. Por exemplo, em países federativos (como é o caso dos Estados Unidos) as unidades participam do processo; já em monarquias (como acontece no Japão, no Marrocos, e na Tailândia) o próprio monarca toma parte nos procedimentos. O ponto aqui é que o emendamento constitucional costuma refletir aspectos do ordenamento do estado que normalmente não afetam de igual forma o processo legislativo ordinário.

Os diferentes procedimentos operam em ordenamentos políticos variados e não apenas os refletem como também são necessariamente influenciados por eles. Saber de fato qual o custo da formação de uma maioria para aprovação de uma emenda requer o estudo do sistema partidário ${ }^{13}$ e do regime político. É intuitivo apontar que um sistema partidário fragmentado apresenta custos maiores para a formação de uma maioria, mas que podem ser minimizados caso haja disciplina partidária e predominância do Executivo. Poder-se-ia ainda prever mais emendas em sistemas unicamerais ou naqueles em que o presidente ou monarca não exerce veto sobre o processo (Levinson, 2001:273).

A taxa de emendamento, diferentemente do processo, ajuda a mensurar o quanto efetivamente ocorre mudança constitucional via emenda. 
A conexão, entretanto, não é óbvia. Uma baixa taxa de emendamento (que pode ser medida em quantidade de emendas por ano ou pela quantidade de texto emendado) pode significar tanto que há uma satisfação com o texto existente quanto que a constituição não é levada a sério e, portanto, não precisa ser modificada.

O processo de emendamento é fundamental para que as novas gerações adequem suas constituições às circunstâncias de seu tempo (Elster, 1988; Holmes, 1988; Lutz, 1994). A mudança constitucional por meio de corpos eleitos possibilita que a atualização ocorra de forma democrática. É este o caso das alterações efetuadas pelas legislaturas, que normalmente têm de mudar a constituição seguindo procedimentos mais exigentes do que os da legiferação ordinária, como prevê o constitucionalismo. $\mathrm{O}$ emendamento feito pelas casas legislativas deve ser considerado no contexto do sistema político-partidário em que está inserido (Levinson, 2001) e, neste caso, a taxa de emendamento indica o quanto os atores de fato utilizam as possibilidades de mudança pela via parlamentar.

O Judiciário também é importante ator na dinâmica constitucional. Seu poder político é derivado da capacidade de exercer revisão judicial ou controle de constitucionalidade ${ }^{14}$ e usualmente advém do próprio texto constitucional, refletindo a escolha dos constituintes por estabelecê-lo ${ }^{15}$. Entretanto, também pode advir de normas não constitucionais ou do ordenamento constitucional do país (Ginsburg, 2003:34), como ocorreu nos Estados Unidos, país que criou o controle de constitucionalidade em 1803, com o célebre caso Marbury v. Madison.

Tal poder é exercido especialmente na interpretação constitucional, e torna-se ainda mais importante quando é possível que a corte retire o poder legal de uma norma infraconstitucional aprovada pelo legislati$\mathrm{vo}^{16} \mathrm{ou}$, ao contrário, dê guarida a decisões legislativas constitucionalmente controversas. Portanto, por um lado, a revisão judicial facilita o enforcement da Constituição ao promover o entendimento sobre o que podem ser transgressões ao texto, inibindo-as (Elkins, Ginsburg e Melton, 2009, loc.4751); por outro, atualiza o texto constitucional para que este acompanhe as preferências políticas majoritárias, mesmo quando estas não contam com apoio suficiente para o emendamento constitucional por outras vias previstas. O Judiciário acaba por ser um agente tanto de continuidade como de mudança. 
Entende-se que ao mesmo tempo que a constituição é defendida pelas cortes, existe uma tensão quando a maioria do povo, por meio de seus representantes, decide por uma lei e esta vem a ser posteriormente desconsiderada por corpos não eleitos. A atuação do Judiciário, entretanto, é restrita e específica; "na medida em que as cortes são contidas [checked] pelos poderes políticos dessas muitas maneiras (ex ante, por meio de nomeações; ex post, por meio de respostas legislativas e constitucionais), as cortes não têm capacidade ilimitada para irem contra as correntes majoritárias" (Comella, 2009:97, tradução livre).

O espaço para atuação do Judiciário é restringido, portanto, por seu desenho institucional. Análogo ao processo de emendamento, o controle de constitucionalidade nos diferentes países apresenta grau significativo de variação. Ginsburg (2003) lista o procedimento de mais de 60 países e define cinco dimensões nas quais os sistemas de revisão judicial variam: acesso à corte ${ }^{17}$; efeito e timing da decisão judicial; mecanismos institucionais de accountability ao ambiente político; tempo de mandato dos juízes; e tamanho da corte. E acrescenta que "graças a numerosas dimensões em que o desenho institucional do sistema de revisão judicial pode variar, existe uma matriz quase infinita de configurações, e não há duas cortes que compartilhem exatamente do mesmo desenho e ambiente institucional" (Ginsburg, 2003:48, tradução livre).

Além dos constrangimentos impostos por seu desenho institucional, o poder de revisão e controle constitucional é também afetado pelo grau de ativismo das cortes. Isto porque "o impacto da revisão judicial depende somente em parte da sua existência formal e, muito mais vitalmente, do vigor e da frequência de seu uso pelas cortes, especialmente cortes constitucionais e supremas" (Lijphart, 1999:225, tradução livre). Portanto, assim como aconteceu com a análise do emendamento constitucional, a efetiva utilização do controle constitucional é tão digna de atenção quanto sua existência formal.

O texto constitucional está, portanto, protegido das frequentes mudanças pela capacidade de mobilizar atores em sua defesa, pelas dificuldades de emendamento e pelo controle de constitucionalidade, e ao mesmo tempo está a salvo da obsolescência por permitir seu aperfeiçoamento via emendamento e revisão judicial.

Nas democracias constitucionais, as constituições usualmente descrevem as relações entre Estado e sociedade, a distribuição de atribuições 
entre diferentes poderes e níveis de governo, e limitam a ação governamental em certas áreas. Além de reduzir a área de atuação estatal, a constitucionalização de direitos (especialmente, mas não exclusivamente, dos direitos positivos) requer ação do Estado para que eles sejam garantidos. Por vezes, a própria constituição dá diretivas para esta ação. O artigo 230 do Capítulo VII da Constituição brasileira parece um bom exemplo dessa situação:

Art. 230. A família, a sociedade e o Estado têm o dever de amparar as pessoas idosas, assegurando sua participação na comunidade, defendendo sua dignidade e bem-estar e garantindo-lhes o direito à vida.

$\S 1$ - - Os programas de amparo aos idosos serão executados preferencialmente em seus lares.

$\S 2$ o- Aos maiores de sessenta e cinco anos é garantida a gratuidade dos transportes coletivos urbanos. (Brasil, 1988)

O direito da pessoa idosa é defendido no caput do artigo. Os dois parágrafos, no entanto, são bem mais específicos e definem políticas mediante as quais o direito será exercido. O parágrafo 2, por exemplo, refere-se especificamente ao direito da pessoa idosa quanto aos transportes coletivos urbanos. Se os direitos positivos eram criticados por serem pouco definidos, o artigo acima indica exatamente o que os governos devem ou não fazer, estipulando políticas (assistência residencial aos idosos e gratuidade do transporte). Para além de definir direitos das pessoas idosas, o artigo define algumas políticas públicas direcionadas a elas. Este é um exemplo do tipo de constitucionalização de política pública que nos interessa.

Analogamente à constitucionalização de direitos, a constitucionalização de políticas públicas reflete a escolha dos atores políticos pelo que é mais bem seguro e protegido: não a mera legislação ordinária, mas a provisão constitucional ${ }^{18}$. O momento da constitucionalização pode ser o da elaboração do texto original ou o do emendamento. O momento constituinte originário pode ser propício para a constitucionalização de políticas públicas, caso as características do processo facilitem a inclusão de interesses particularistas (Couto e Arantes, 2006:44); também é possível que políticas públicas sejam respostas a crises que tenham ensejado o momento constituinte - suscitando a substituição de uma velha ordem constitucional. Por meio do emendamento, a constitucionalização de políticas tanto pode ser uma resposta das autoridades a reclamos populares para que determinada ação governamental se mantenha e cristalize no tempo, quanto pode ser um modo de prote- 
ger uma política das tentativas de mudança feitas por aqueles que a ela se opõem.

Com a constitucionalização de políticas, para implementar uma agenda divergente da ordem dada, um governo terá que formar coalizões que superem os requisitos para alteração do texto constitucional, transpondo a resistência de grupos organizados em defesa da constituição. Isto pode ser apontado como positivo, pois eleva o grau de consensualismo do jogo político. No entanto, também é possível prever que haverá retardamento das decisões, com possível perda de eficácia governamental; as minorias do Legislativo podem ganhar força extraordinária (Arantes e Couto, 2010) e a alteração de partidos no poder pode não ser traduzida na alteração de políticas públicas pela incapacidade de modificar políticas constitucionalizadas.

Ao incorporar políticas públicas, as constituições tendem a se tornar alvo de constantes tentativas de alteração, pois se tornam o locus da implementação de políticas governamentais; como políticas podem perder sua eficácia ao não corresponder a preferências do grupo político governante, instala-se o processo de emendamento. Se a tentativa de alteração frequente fracassar - por dificuldades excessivas de emendamento ou a não formação dos requisitos necessários para a alteração geram-se incentivos a um possível repúdio do ordenamento constitucional (idem). No limite, as consequências da constitucionalização de políticas públicas para o jogo político e para a própria constituição podem ser nefastas, levando "a um enrijecimento injustificado de questões que-por sua própria natureza-deveriam permanecer suscetíveis à alternância de partidos no poder" (ibidem:577).

A incorporação de políticas públicas tem também consequências para o funcionamento do Judiciário e sua força institucional, analogamente ao que se verifica com a constitucionalização de direitos. Isto porque a constitucionalização de qualquer assunto aumenta a probabilidade de que as cortes sejam acionadas com mais frequência e sobre mais temas.

Uma constituição, portanto, pode influenciar as políticas públicas não apenas por prover a estrutura sobre a qual elas serão desenhadas, ou por fixar limiares de onde elas devem partir e limites até onde elas podem chegar, mas também porque as políticas podem estar incorporadas à Carta. Para formular hipóteses sobre as consequências da constitucionalização de políticas para o jogo político, para a constituição que as incorpora e para as próprias políticas constitucionalizadas - objeti- 
vo deste artigo - é necessário saber mais sobre a natureza e a dinâmica das políticas públicas, assunto da próxima seção.

\section{DINÂMICA DAS POLÍTICAS PÚBLICAS}

Nesta seção, pretendemos discutir a dinâmica de continuidade ou mudança de políticas públicas, isto é, quais são os fatores responsáveis pela manutenção de políticas vigentes, sua alteração ou substituição e os processos mediante os quais isto ocorre. Isto pode ser discutido tanto de uma perspectiva mais geral, que considere os diversos fatores relevantes para a manutenção ou para a mudança de uma política e o peso de cada um deles, como também de formas mais específicas, considerando particularmente um ou outro fator. $\mathrm{O}$ estatuto jurídico da política é um desses fatores, e aí se insere a questão dos efeitos da eventual constitucionalização da política pública - problema abordado neste artigo.

Uma política pública é composta por três elementos: (1) objetivos, (2) instrumentos para que se alcancem os objetivos definidos, e (3) parâmetros ou especificações destes instrumentos (Hall, 1993:278). Os objetivos são aquilo que a política pública busca concretizar; os instrumentos são os meios de concretização dos objetivos da política; e os parâmetros são as especificações detalhadas dos meios da política. Assim, uma política com determinados objetivos pode ter seus instrumentos escolhidos dentro de uma série de alternativas, que podem assumir diferentes valores em seus parâmetros. "Por exemplo, se o objetivo da política é aliviar os problemas financeiros dos idosos, o instrumento escolhido pode ser uma pensão para idosos [old age pension], e seu parâmetro [setting] seria o nível no qual os benefícios forem fixados" (Hall, 1993:278, tradução livre).

Com base na variação dos três elementos das políticas, Peter Hall (1993) sugere três ordens de mudança que possibilitam entender o quanto uma política muda, continua ou é interrompida.

(a) A primeira ordem de mudança corresponde à alteração da variável mais simples, os parâmetros dos instrumentos da política, enquanto os instrumentos em si e os objetivos da política permanecem os mesmos. Essa mudança corresponderia, no exemplo brevemente utilizado acima, a alterações nos valores das pensões destinadas aos idosos ou na idade de corte para o recebimento do benefício, sendo que o instrumento (o oferecimento de uma pensão com base na idade dos benefi- 
ciários) continuaria o mesmo, assim como o objetivo (aliviar problemas financeiros dos idosos).

(b) A segunda ordem modifica a ambos - os parâmetros e os instrumentos da política -, enquanto a hierarquia de objetivos mantém-se inalterada. Em uma política de alfabetização universal, por exemplo, pode-se alterar da provisão direta de serviços para a utilização de vouchers.

(c) A terceira ordem marca uma quebra clara com o passado, já que os três elementos são alterados simultaneamente. Essas mudanças são mais raras, e podem ser exemplificadas pela passagem de uma política macroeconômica keynesiana para uma monetarista ${ }^{19}$.

A primeira e a segunda ordem de mudanças, em que se alteram especificações e instrumentos, "preservam as continuidades usualmente encontradas nos padrões de política" (Hall, 1993:279; tradução livre), enquanto apenas a terceira ordem é considerada um processo de maior ruptura, associado a períodos de descontinuidades na política (Hall, 1993:279). Isto não quer dizer que a escolha dos instrumentos para atingir os objetivos em uma determinada política não seja contenciosa. Pelo contrário, ela frequentemente é um dos principais objetos da disputa política cotidiana entre partidos e grupos de interesse, e pode acarretar mudanças significativas na vida dos cidadãos. Outro objeto comum de controvérsia política são os parâmetros das políticas. Porém, sua frequente atualização é normalmente uma condição necessária à própria continuidade da política - noutros termos, para continuar é preciso mudar (Thelen, 2003; Hacker, 2004; Pierson e Hacker, 2010).

Quando há excessiva estabilidade das políticas, definida aqui pela não mudança, pode-se ter consequências negativas para a eficácia e eficiência no que diz respeito a atingir os objetivos da política (Thelen, 2003; Hacker, 2004; Pierson e Hacker, 2010). Esse descompasso (drift) entre os objetivos da política e seus efeitos acontece graças às mudanças no ambiente das políticas (policy environment) ${ }^{20}$. O descompasso entre uma política e seus objetivos chama atenção para as duas primeiras ordens de mudança descritas acima. Uma mudança dos parâmetros dos instrumentos de uma política - como os valores das regras de elegibilidade para um programa social - tem impacto profundo nos efeitos da política e na vida dos cidadãos. A ausência de mudança, por sua vez, pode reverter preferências e coalizões antes favoráveis à política, já que esta deixa de alcançar seus objetivos. Assim, a estabilidade do 
desenho da política pode se reverter em instabilidade no longo prazo e, potencialmente, em descontinuidade.

Feita tal ponderação, consideramos que a continuidade da política pública se dá apenas quando não há mudança nem em seus instrumentos e nem em seus objetivos, enquanto os parâmetros podem ser modifica$\operatorname{dos}^{21}$.

O que explica a continuidade ou a mudança de políticas públicas são os mecanismos de reprodução (Thelen, 1999:387), ou seja, os diversos fatores endógenos ou exógenos que contribuem para que uma política pública se mantenha no tempo, gerando equilíbrios estratégicos, incentivos aos atores, etc. ${ }^{22} \mathrm{~A}$ explicitação de tais mecanismos "é crucial para entender as diferenças em duração dos legados" institucionais e "quais tipos de eventos ou processos têm a capacidade de minar tais legados" (ibidem:392). Em nosso caso, a explicitação dos mecanismos determinantes para que uma política pública se mantenha (ou não) é o que permitirá compreender o eventual efeito de fatores endógenos (como a resiliência da política) ou exógenos (como sua constitucionalização) na sua continuidade.

A resiliência da política ocorre quando há significativa resistência a mudanças em função de características intrínsecas à política, que levam atores políticos a apoiá-la, podendo resultar em continuidade (Pierson, 2000, 2006). Mais de um mecanismo pode estar em funcionamento para que haja continuidade da política:

Na verdade, arranjos altamente resilientes frequentemente repousam sobre esse tipo de "redundância", de modo que mesmo que um mecanismo seja interrompido, o equilíbrio pode não ser. Também é possível que o principal mecanismo de reprodução mude ao longo do tempo. Por exemplo, uma instituição que inicialmente assenta-se na sua capacidade de promover a coordenação entre atores pode dar origem a grupos poderosos que passam a proteger a instituição mesmo que seu papel de coordenação se deteriore. (Pierson, 2000:78, tradução livre)

Nesta passagem, Paul Pierson aponta duas fontes de resiliência de uma política pública:

(1) a existência de uma coalizão de apoiadores, isto é, atores que, por diferentes razões, são beneficiados pela manutenção da política pública. Pode ser formada tanto por seus beneficiários (o público-alvo), como 
pela burocracia responsável por sua implementação, fornecedores do Estado, entes regulados etc.;

(2) problemas de coordenação, que resultam dos custos de recoordenação dos múltiplos atores: “Uma vez que a coordenação está no lugar e as pessoas estão seguindo-a, o custo de recoordenação éo obstáculo maior para mudar para qualquer ordem superior. Esse custo pode bloquear a recoordenação ainda que seja virtualmente do interesse de todos estar em uma nova ordem" (Hardin, 1999:16, ênfases do autor, tradução livre). Apesar de improvável, não é impossível que os custos sejam transpostos, ocasião na qual qualquer outro equilíbrio pode ser alcançado. $\mathrm{O}$ novo equilíbrio não é necessariamente similar ao antigo e não há como prever qual equilíbrio será alcançado (Pierson, 2004:144).

Ainda segundo Pierson, "juntos, esses fatores frequentemente tornam a revisão significativamente difícil. Igualmente importante, eles influenciam as condições sob as quais as revisões serão possíveis e favorecem certos tipos sobre outros" (ibidem:142, tradução livre).

Políticas públicas em vigor criam jogos políticos ${ }^{23}$. A criação de uma nova política pública pode reconfigurar a dinâmica política ao alterar a capacidade do governo, criando ou fortalecendo incentivos para ação coletiva, e induzindo compromissos sociais difíceis de reverter, criando ciclos autossustentáveis e inviabilizando alternativas de mudança (Patashnik e Zelizer, 2009:2). Isto é o que se chama de policy feedback, "um processo causal entre as escolhas de política pública em t1 e as condições sob as quais a política é decidida em $\mathrm{t} 2$ " (Jacobs e Weaver, 2010:3, tradução livre) que pode ter forma positiva ou negativa. O feedback positivo é aquele que aumenta os benefícios relativos (ou reduz os custos relativos) das políticas presentes quando comparadas a suas alternativas concebíveis (idem). Já o negativo teria o sinal oposto, ou seja, aumentaria os custos (ou reduziria os benefícios) das políticas presentes quando comparadas a suas alternativas.

O argumento principal, portanto, é que políticas passadas moldam e limitam escolhas e resultados subsequentes (ibidem:1). O fato de uma política iniciar um processo de feedback positivo não significa que ela continuará completamente inalterada ou intocável em função de aumentar os benefícios relativos de atores políticos cruciais (grupos de interesse, elites de governo, atores influentes na opinião pública), mas sim que ela cria condições mais propícias à sua preservação. Como diz Pierson (2004:147), “em vez de refletirem os benefícios (funcionais) de 
troca institucionalizada, a continuidade institucional (ou fortes tendências para apenas ajustes incrementais) podem refletir o custo crescente da adoção de alternativas antes disponíveis". Assim, a política em vigor cria ela mesma os mecanismos favoráveis à sua autossustentação (self-reinforcement).

Por outro lado, como apontam Jacobs e Weaver (2010:13-14) feedbacks positivos podem levar à expansão de uma política pública de modo a provocar a transformação de sua própria natureza - e, neste sentido, levam à sua descontinuidade. Em um exemplo dado pelos autores, uma política de seguro saúde pode fazer tanto sucesso que leva à sua transformação num serviço público de saúde. Inversamente, uma situação de feedback negativo, na medida em que incentiva os atores a promoverem ajustes incrementais na política pública, corrigem-na, preservando-a.

Portanto, estabilidade e mudança podem resultar dos mesmos tipos de mecanismo. Sabendo quais deles estão em funcionamento e quais processos engendram em cada contexto específico, pode-se compreender seu potencial, suas vulnerabilidades e estratégias de mudanças mais prováveis (Pierson, 2000; Thelen, 2003; Hacker, 2004; Pierson e Hacker, 2010). Enfim, para um quadro completo da mudança das políticas públicas, precisamos entender quem forma a coalizão de atores que apoiam a política, quais são os problemas de coordenação envolvidos e a capacidade das políticas em serem self-binding, integradamente aos fatores sociais, econômicos, políticos e - especialmente - institucionais.

Na próxima seção, formulamos hipóteses sobre como a constitucionalização altera a continuidade das políticas ao impor sua lógica ao funcionamento das políticas públicas constitucionalizadas. O tipo de mudança engendrado nas políticas será resultado da combinação das fontes de resiliência e do status constitucional - ou seja, do quanto a política pública é ou não resguardada pela normatividade constitucional.

\section{MODELO DE ANÁLISE}

A variável dependente do modelo de análise proposto aqui é a continuidade das politicas públicas e pode ser definida como a permanência dos mesmos objetivos e instrumentos ao longo do tempo. A continuidade, então, deve ser entendida como um processo temporal e medida por meio da comparação entre, no mínimo, dois momentos (t1 e t2). 
Haverá descontinuidade quando os objetivos e/ou instrumentos da política em $\mathrm{t} 2$ forem diferentes daqueles estabelecidos em $\mathrm{t} 1$.

A literatura de políticas públicas nos informa que, de uma maneira geral, as políticas têm continuidade quando possuem várias fontes de resiliência - são, para um determinado problema, uma solução cujo custo de recoordenação é proibitivo (inclusive porque o investimento dos atores interessados em sua manutenção é elevado) e/ou a coalizão de apoio é ampla. Em caso de ausência das fontes de resiliência, a política estaria sujeita à mudança mais facilmente, e uma vez que se torne instável (exista interesse em sua mudança) ${ }^{24}$, a trajetória mais provável será a de descontinuidade (Hardin, 1999:16; Thelen, 1999:387; Pierson, 2000:78; Pierson, 2004:142; Patashink e Zelizer, 2009:2; Jacobs e Weaver, 2010:41).

A constitucionalização de uma política altera essa dinâmica, pois implica que a partir daquele momento ela está sujeita às regras e aos processos constitucionais. Portanto, para a continuidade de uma política pública faz diferença que ela esteja ou não constitucionalizada. A não constitucionalização supõe que a política apresentará uma dinâmica pautada apenas pelos elementos levantados na seção anterior. A constitucionalização, por sua vez, traz consigo os elementos explorados na seção precedente, acerca da dinâmica constitucional. Assim, além das fontes de resiliência provenientes do funcionamento da política, temos que considerar o efeito da possível constitucionalização para determinarmos a trajetória da política. Portanto, são duas as variáveis explicativas propostas: (1) suas fontes de resiliência e (2) seu status constitucional.

A variável fontes de resiliência está relacionada à tendência de continuidade da política pública pelos seus próprios méritos, independentemente de seu estatuto jurídico. Ela é composta por (a) uma coalizão de apoio à política, (b) os custos de recoordenação e (c) o tipo de feedback que a política possui. As características de cada um destes elementos dependerão do sistema político e da política de que se trata, e suas variações podem assumir diversas formas. Para a elaboração do argumento, trabalhamos aqui com graus alto e baixo de resiliência. Quando a política tem ao menos duas fontes como fatores inibidores de mudanças, entendemos que seu grau de resiliência é alto. Um grau baixo significa que no máximo uma dessas fontes contribui significativamente para sua resiliência. Argumentamos que a coalizão contrária à política, inte- 
ressada em sua mudança ou descontinuidade, enfrentaria custos contornáveis quando da presença de apenas uma fonte de resiliência. $\mathrm{Na}$ presença de duas ou três fontes, no entanto, prevê-se que a coalizão contrária à política deva ser significativamente maior que a de apoio, ou precisará despender uma quantidade considerável de recursos para transpor a resiliência encontrada.

A segunda variável, que denominamos status constitucional, serve para avaliar a importância da constitucionalização para a continuidade de políticas, independentemente da sua resiliência decorrente dos outros fatores apontados. É preciso deixar claro que diferença faz as políticas estarem ou não constitucionalizadas, de qual tipo de constituição se trata e o grau de constitucionalização - todos estes elementos serão definidos adiante.

Uma política pode ou não estar constitucionalizada, ou seja, pode ou não estar incluída no texto constitucional ${ }^{25}$. Não estando textualmente constitucionalizada, a política continua operando sob o ordenamento constitucional, sujeita aos limites impostos pela constituição - e, neste caso, o seu status constitucional é baixo, já que, ao não constar do texto, ela está no limite mais baixo do continuum de constitucionalização. A política pode ainda responder a uma demanda do texto (caso garanta um direito positivo constitucionalizado, por exemplo), ou pode encontrar suas justificativas e bases no texto ${ }^{26}$. A política, no entanto, não está sujeita à dinâmica de mudança constitucional no que concerne às regras de emendamento, e não se beneficia da mobilização envolvida na política constitucional, tal como ocorre com as políticas constitucionalizadas.

Sendo constitucionalizada, resta saber sobre qual constituição se fala. Há muitas variações que influenciam a dinâmica constitucional e, por isso, a política: a flexibilidade do processo de emendamento, a força e a independência do judiciário no tocante ao controle de constitucionalidade, e a capacidade mobilizadora da constituição. Tais diferenças na composição da proteção constitucional aparecem tanto ao longo do tempo quanto entre países. Imaginamos que um rígido processo de emendamento aliado a um forte controle de constitucionalidade em uma constituição reverenciada resulte em um alto nível de proteção constitucional, enquanto, na outra ponta do espectro, estariam constituições com processo de emendamento relativamente fácil, judiciário sem capacidade de controle constitucional e uma constituição com 
pouca capacidade mobilizadora (ou seja, que não chega a galvanizar apoios intensos a seus dispositivos meramente pelo fato de integrarem o texto constitucional) ${ }^{27}$.

Na mesma constituição, todos os dispositivos estão potencialmente sujeitos ao mesmo grau de proteção constitucional, exceto quando alguns deles são declarados inalteráveis (cláusulas pétreas), requerem procedimentos diferenciados de alteração ou não são judiciáveis (em ambos os casos, claramente, a proteção é diferenciada institucionalmente). Apenas potencialmente a proteção é a mesma para todos os dispositivos reunidos em uma constituição, pois o uso efetivo da constitucionalização depende da natureza do conteúdo e de sua ativação pelos atores políticos. Assim, o judiciário provavelmente será mais ativado para garantir a implementação de algumas partes do texto constitucional do que de outras, e o poder de mobilização da constituição será maior sobre determinados assuntos do que sobre outros. Desse modo, dentre as políticas públicas constitucionalizadas, é possível prever que a força da constitucionalização seja desigual em uma mesma constituição, entre países, ao longo do tempo em um mesmo país, e entre diferentes tipos de política.

Os efeitos da constitucionalização sobre a continuidade das políticas variam em função dos elementos da política (objetivos, instrumentos e parâmetros) que foram constitucionalizados e de sua dependência para com a legislação infraconstitucional. É possível que apenas os objetivos da política sejam constitucionalizados, ou seus objetivos e seus instrumentos, ou ainda que os três elementos da política sejam incluídos na constituição.

Pode-se, assim, pensar em três graus distintos de constitucionalização de políticas públicas: (1) grau baixo, quando apenas os objetivos são constitucionalizados; (2) grau médio, quando a constitucionalização avança até os instrumentos; (3) grau alto, quando até mesmo parâmetros da política são constitucionalizados. Quanto mais alto o grau da constitucionalização, mais detalhada e potencialmente controversa ela é, tendendo a ser menor a necessidade de regulação infraconstitucional e vice-versa; noutros termos, mais se tem policy e menos polity ${ }^{28}$. O grau da constitucionalização será fundamental para entender sua importância para a implementação e a continuidade das políticas.

No que diz respeito à implementação, uma consequência importante do grau de constitucionalização concerne à autoaplicabilidade ou não da política. Isto 
porque, quando a constitucionalização contiver apenas os objetivos da política, esta precisará ser regulamentada via legislação infraconstitucional, dada sua vaguidão quanto à operacionalização. Isto suscita duas possibilidades. A primeira delas é a de que a legislação suplementar não seja feita, o que poderia resultar na não implementação da política. Contudo, havendo grau médio de constitucionalização (dos instrumentos), ainda é possível imaginar que a falta de regulação de seus parâmetros seja um fator dificultador da implementação da política, pois requer legislação complementar. E, por fim, nos casos em que a política é constitucionalizada, mas há menção explícita à necessidade de sua regulação, supomos que tal requerimento enfraqueça os possíveis efeitos automáticos da constitucionalização, pois, neste caso, a ausência de regulação pode ser condição jurídica suficiente para que atores contrários à política garantam sua não implementação com base na não autoaplicabilidade ${ }^{29}$.

A segunda possibilidade suscitada pela necessidade de regulação via legislação infraconstitucional é a maior discricionariedade dos atores políticos para elaboração e mudança deste tipo de norma, que na maioria das vezes não está submetida a regras de aprovação e alteração tão rígidas quanto as necessárias para modificar o texto constitucional. Assim, a política pode ser regulada e alterada mais facilmente ao longo do tempo.

A variável status constitucional é definida, portanto, pelo nível de proteção de que dispõe os dispositivos e objetos constitucionalizados da política. Ela é composta pelos seguintes elementos: (1) facilidade/dificuldade de emendamento ou revisão $\mathrm{o}^{30}$; (2) papel do judiciário no controle de constitucionalidade (mais ou menos proeminente); (3) grau de constitucionalização das políticas (nos termos postos acima). À semelhança da variável fontes de resiliência, a variável status constitucional também opera em graus. Uma política pública apresenta status constitucional de grau alto quando ao menos duas das seguintes características estão presentes: 1) está inserida em uma constituição cujo emendamento é difícil, pois a constituição é rígida e com forte capacidade mobilizadora; 2) o Poder Judiciário exerce ativamente o controle constitucionalidade e 3) os objetivos e instrumentos da política estão constitucionalizados. Já uma política pública cujo status constitucional é baixo está pouco protegida das tentativas de mudança, pois ao menos duas das seguintes condições estão presentes: 1) a constituição na qual está inserida é facilmente modificável; 2) o Judiciário não exerce con- 
trole constitucional; 3) apenas seus objetivos estão vagamente inseridos no texto.

A continuidade das políticas públicas constitucionalizadas decorre da combinação de sua resiliência com seu status constitucional. A interação entre estas duas variáveis informa o efeito da constitucionalização sobre a continuidade da política constitucionalizada. O Quadro 1 a seguir mostra o efeito esperado da constitucionalização de políticas na sua continuidade.

Quadro 1

Efeito da Constitucionalização sobre a Continuidade de Políticas Públicas

\begin{tabular}{|c|c|c|c|}
\hline & \multicolumn{2}{|l|}{ Status Constitucional } \\
\hline & & Alto & Baixo \\
\hline \multirow{2}{*}{$\begin{array}{l}\text { Fontes de } \\
\text { Resiliência }\end{array}$} & Alta & $\begin{array}{c}\text { Curto prazo: Redundante } \\
\text { Longo prazo: risco de descompasso }\end{array}$ & Neutro \\
\hline & Baixa & $\begin{array}{c}\text { Curto prazo: Indispensável } \\
\text { Longo prazo: mudança no apoio à política }\end{array}$ & Insuficiente \\
\hline
\end{tabular}

Fonte: Elaboração própria.

O quadrante superior esquerdo indica que não se espera nenhum efeito da constitucionalização na continuidade da política a curto prazo, pois ela já é garantida pela resiliência. A longo prazo, a constitucionalização pode até mesmo se tornar prejudicial à política, caso represente uma barreira muito grande a mudanças incrementais, ajustes e aprimoramentos. O engessamento da política pode significar descompasso entre seus efeitos e seus objetivos nas novas conjunturas, o que reduziria a resiliência, levando a política à condição prevista no quadrante inferior esquerdo, quando apenas seu status constitucional garante sua continuidade. No extremo, o descompasso faria com que alguns agentes atuassem para desconstitucionalizar a política.

O quadrante inferior esquerdo indica que o efeito da constitucionalização é indispensável para a continuidade da política: ela depende da proteção constitucional para se manter, pois não é inerentemente resistente a mudanças. De forma inversa ao fenômeno previsto no primeiro quadrante (o descompasso), no longo prazo e com o auxílio da proteção constitucional, é possível que a política desenvolva suas próprias fontes de resiliência, fazendo com que a constitucionalização se torne potencialmente benéfica para sua continuidade. Isto, contudo, não é garantido, pois não se pode descartar uma piora no que concerne à re- 
siliência pelo aumento da rejeição à política a médio ou longo prazos por um número cada vez maior de atores caso ela se mostre insustentável ou intolerável. Neste caso, mesmo a proteção constitucional será insuficiente para assegurar a continuidade da política, levando à sua interrupção por meio do emendamento da constituição.

O quadrante superior direito indica que há pouca proteção constitucional a tentativas de mudança da política e que, ao mesmo tempo, sua resiliência é alta. A continuidade da política é garantida pela resiliência, portanto, o efeito da constitucionalização sobre ela é neutro: não sendo fator de proteção da política, também não afeta negativamente sua continuidade, já que não representa impedimentos a ajustes importantes em seus parâmetros ou instrumentos ao longo do tempo.

O quadrante inferior direito indica que o efeito esperado da constitucionalização é insuficiente para garantir a continuidade da política, pois tanto a proteção que a constituição lhe fornece é baixa, como suas fontes de resiliência não estão desenvolvidas, de modo que tentativas de mudança encontram poucos obstáculos.

Cada uma das variáveis independentes em seu grau elevado é, individualmente, condição suficiente para garantir a continuidade das políticas constitucionalizadas; não são, entretanto, individualmente necessárias, já que é possível que apenas uma delas promova a continuidade. O Quadro 2 nos informa a trajetória esperada das políticas públicas a curto prazo para cada efeito da constitucionalização previsto no Quadro 1.

\section{Quadro 2}

Trajetória de Curto e Médio Prazos das Políticas Públicas Constitucionalizadas

\begin{tabular}{|c|c|c|c|}
\hline & \multicolumn{2}{|l|}{ Status Constitucional } \\
\hline & & Alto & Baixo \\
\hline \multirow[b]{2}{*}{$\begin{array}{l}\text { Fontes de } \\
\text { Resiliência }\end{array}$} & Alto & Continuidade & Continuidade \\
\hline & Baixo & $\begin{array}{l}\text { Continuidade no curto prazo/ Possível } \\
\text { descontinuidade no médio e longo prazos }\end{array}$ & Descontinuidade \\
\hline
\end{tabular}

Fonte: Elaboração própria a partir do Quadro 1.

Sumarizando nossas conclusões, podemos afirmar que políticas públicas com alto grau de resiliência terão continuidade, independentemente de seu status constitucional. Já quando a política pública apresenta baixo grau de resiliência, o status constitucional é o elemento 
definidor de sua trajetória: sendo elevado, a continuidade da política está, em princípio, garantida; sendo baixo, tende a implicar descontinuidade caso o grau de resiliência não seja suficientemente alto para mantê-la.

A título de exemplo do potencial de aplicação do modelo, consideremos duas políticas públicas constitucionalizadas no Brasil: o Sistema Único de Saúde (SUS) e o monopólio estatal das telecomunicações. Para ambas, é preciso verificar cada um dos elementos que constituem as variáveis independentes, bem como a dependente, qual seja, sua continuidade.

No caso do SUS, trata-se de uma política com forte coalizão de apoio, alto custo de recoordenação e feedback positivo. Tem seus objetivos e instrumentos constitucionalizados em um país cujo judiciário exerce controle de constitucionalidade, embora esteja inscrita em um texto recorrentemente emendado. Sua continuidade pode ser verificada pelos gastos realizados com a política, a existência e contínuo investimento em unidades e profissionais de saúde, bem como a quantidade de atendimentos. Mais ainda, a normatização do SUS no plano constitucional tem sido contínua, sempre com emendas que tiveram o condão de reforçá-lo ou regular sua implementação, jamais com o propósito de descontinuá-lo. Ou seja, como apontam Arantes e Couto (2008), a constitucionalização de políticas públicas num dado momento tem como corolário o aprofundamento de sua constitucionalização em momentos posteriores. O Quadro 3 traz um sumário da atividade constitucional relativa ao SUS.

O monopólio estatal das telecomunicações, por sua vez, com baixas fontes de resiliência, em uma constituição facilmente emendável, em que não apenas seu objetivo estava inserido no texto constitucional, mas também seus instrumentos (o caráter estatal dos serviços de telecomunicações) foi retirado da Constituição brasileira e descontinuado por ocasião das reformas do Estado promovidas na esteira do Plano Real. Isso ocorreu menos de sete anos após a promulgação da nova Carta (Emenda Constitucional no 8/1995). O fato dos instrumentos estarem constitucionalizados, se por um lado protegia a política pública de baixa resiliência ao tornar mais custosa a sua modificação, por outro lado atraia para o interior do texto constitucional a disputa política cotidiana pela agenda governamental. 


\section{Quadro 3}

Normatização Constitucional do SUS pelo Constituinte Derivado

\begin{tabular}{|l|l|}
\hline Emenda Constitucional & \multicolumn{1}{|c|}{ Teor } \\
\hline $20 / 1998$ & $\begin{array}{l}\text { Determinou a regulação por lei dos critérios de } \\
\text { transferências de recursos para o SUS. }\end{array}$ \\
\hline $29 / 2000$ & $\begin{array}{l}\text { Fixou limiares de gasto público em saúde e definiu fontes } \\
\text { de recursos. }\end{array}$ \\
\hline $51 / 2006$ & $\begin{array}{l}\text { Estipulou e regulou a contratação de agentes comunitários } \\
\text { de saúde pelos gestores locais do SUS. }\end{array}$ \\
\hline $63 / 2010$ & $\begin{array}{l}\text { Determinou a regulação legal de pisos salariais e regime } \\
\text { jurídico dos agentes comunitários de saúde e agentes de } \\
\text { combate a endemias, bem como definiu que a União } \\
\text { auxiliaria os governos subnacionais a arcar com a } \\
\text { remuneração destes agentes. }\end{array}$ \\
\hline $85 / 2015$ & $\begin{array}{l}\text { Estipulou como competência do SUS também incrementar } \\
\text { o desenvolvimento científico e tecnológico. }\end{array}$ \\
\hline $86 / 2015$ & $\begin{array}{l}\text { Definiu o percentual mínimo de 15\% dos da receita } \\
\text { corrente líquida da União como gasto em saúde, dentre } \\
\text { outras providências. }\end{array}$ \\
\hline
\end{tabular}

Fonte: Brasil. Constituição Federal de 1988 e respectivas emendas.

O caráter controverso da política, um dos fatores de sua resiliência, acabou por enfraquecê-la numa conjuntura marcada pela preferência cada vez mais disseminada (especialmente entre os componentes da coalizão governamental) por reduzir a participação estatal em diversas áreas, privatizando-as ou concedendo-as à iniciativa privada. Foi isto o que tornou possíveis as diversas emendas constitucionais de caráter liberalizante do período Fernando Henrique Cardoso, dentre as quais a que sacramentou o fim do monopólio estatal das telecomunicações (Couto e Abrucio, 2003:278). Ou seja, se nos primeiros anos de vigência da nova Carta a constitucionalização da política serviu para resguardá-la de eventuais tentativas de mudança, tal resguardo não foi suficiente diante de uma conjuntura política favorável à sua mudança e contando com uma coalizão amplamente majoritária, capaz inclusive de emendar a constituição. Neste caso, conforme previsto no modelo (ver Quadro 1), produziu-se uma alteração do apoio à política em relação ao existente no momento de promulgação da constituição, reduzindo-o.

Um caso distinto é o da Lei de Responsabilidade Fiscal (LRF), uma política que não foi contemplada pelo texto da Constituição - o capítulo sobre as "Finanças Públicas" da Constituição de 1988 é regulamentado 
por uma lei complementar. Apesar de inúmeras tentativas de modificá-la, a LRF permanece inalterada desde a sua promulgação, em maio de 2000. Desde então, contabilizam-se na Câmara dos Deputados 321 projetos de alteração da lei, nenhum deles transformado em norma jurídica ${ }^{31}$. O ponto é que sua resiliência é alta, pois existe um consenso razoavelmente estabelecido sobre a importância de sua manutenção, o que tornou as iniciativas para modificá-la inviáveis. Em vez disso, foi aprovada legislação que a reforçou, como a Lei de Crimes Fiscais de 2000 e a Lei Anticorrupção de 2013 (Brasil, 2016). Deste modo, o fato de tal legislação não ter sido constitucionalizada em nada prejudicou a sua continuidade, conforme previsto pelo modelo e indicado no Quadro 2.

Por fim, a legislação eleitoral é exemplo de um conjunto de normas que, mesmo se constituindo em regras do jogo político, tendo assim natureza de policy constitutiva (Lowi, 1972), não logrou amplo consenso político, apresentando baixa resiliência e sofrendo frequentes modificações. Para isto, o fato de não dispor de proteção constitucional mostra-se um facilitador. Como exemplo, podemos citar a Lei das Eleições de setembro de 1995, alterada por nova lei já no ano seguinte e, depois, revogada em boa parte por uma nova Lei das Eleições de 1997. Todas elas, note-se, também alteraram dispositivos do Código Eleitoral de 1965. A lei de 1997, por sua vez, também foi bastante modificada posteriormente, com diversos dispositivos acrescidos, alterados ou revogados por nada menos que cinco outras leis $(1999,2006,2009,2013$ e 2015). As leis aprovadas em 1997, 2006, 2009 e 2013 tiveram diversos dispositivos anulados por Ações Diretas de Inconstitucionalidade (em 2002, 2006, 2011 e 2015, respectivamente). Em suma, no espaço de 20 anos, um total de oito leis e quatro decisões judiciais de controle consti-

Quadro 4

Exemplos de Políticas de Acordo com seu Status Constitucional e suas Fontes de Resiliência

\begin{tabular}{|c|c|c|c|}
\hline & \multicolumn{2}{|c|}{ Status Constitucional } \\
\hline & & Alto & Baixo \\
\hline \multirow{2}{*}{$\begin{array}{l}\text { Fontes de } \\
\text { Resiliência }\end{array}$} & Alto & $\begin{array}{c}\text { Sistema Único de Saúde } \\
\text { Continuidade }\end{array}$ & $\begin{array}{l}\text { Lei de Responsabilidade Fiscal } \\
\text { Continuidade }\end{array}$ \\
\hline & Baixo & $\begin{array}{l}\text { Monopólio Estatal das } \\
\text { Telecomunicações } \\
\text { Descontinuidade }\end{array}$ & $\begin{array}{l}\text { Legislação Eleitoral } \\
\text { Descontinuidade }\end{array}$ \\
\hline
\end{tabular}

Fonte: Elaboração própria a partir dos Quadros 1 e 2. 
tucional alteraram substantivamente a legislação eleitoral no Brasil, indicando claramente que uma área pouco resiliente e de baixo status constitucional torna-se bastante propícia à descontinuidade normativa, conforme previsto pelo modelo e indicado no Quadro $2^{32}$.

\section{CONSIDERAÇÕES FINAIS}

O intuito deste artigo foi contribuir para o entendimento do efeito que a eventual constitucionalização das políticas públicas pode ter para sua continuidade. Para tal, analisamos o problema à luz de questões levantadas por duas vertentes da literatura. Por um lado, a produção de ciência política que lida com a questão do constitucionalismo; por outro, aquela referente à análise de políticas públicas que se ocupa particularmente do problema da continuidade.

O exame da literatura de constitucionalismo foi importante para esta análise porque abordou as formas pelas quais constituições protegem seu texto: a capacidade que têm de mobilizar cidadãos em sua defesa e as regras de emendamento e de controle de constitucionalidade, que variam bastante entre países e ao longo do tempo em um mesmo país inclusive entre os dispositivos de um mesmo texto num dado momento. Os diferentes níveis de proteção entre dispositivos da mesma constituição se dão especialmente entre artigos de naturezas distintas - regras do jogo, direitos ou políticas públicas. A tendência é que as últimas sejam muito mais suscetíveis a modificações do que os dois primeiros, embora possa haver exceções a esta tendência - como demonstra a volubilidade da legislação eleitoral no Brasil.

O exame da literatura sobre políticas públicas mostrou que sua continuidade também é afetada por uma série de fatores. Uma coalizão de interessados, problemas de coordenação e investimentos dos atores, quando presentes e em diferentes intensidades, são aspectos relevantes para a continuidade das políticas públicas. A constitucionalização, portanto, é mais um destes fatores. Quando constitucionalizadas, as políticas passam a ter sua alteração submetida a regras procedimentais mais exigentes (como é o padrão para alterações constitucionais), contam com a proteção assegurada pelos tribunais ao texto das constituições e revestem-se de uma reverência social maior (conferida a tudo o que é constitucional). Todos estes fatores conjugados tendem a elevar substancialmente os custos de alteração das políticas, favorecendo assim o status quo. 
O modelo analítico proposto aqui para entender a continuidade das políticas públicas constitucionalizadas combina a proteção conferida pelo status constitucional das políticas a suas fontes de resiliência. Por um lado, a constitucionalização importa para a continuidade das políticas quando a constituição dispõe de mecanismos que a protegem: os cidadãos se mobilizam em sua defesa, as regras de emendamento são difíceis, e o judiciário é independente e dotado do poder de exercer o controle de constitucionalidade. Por outro lado, a constituição é relevante quando a policy não possui fontes de resiliência por si só: são poucos e/ ou fracos os atores interessados na sua preservação, os problemas de coordenação em prol de uma alternativa podem ser facilmente superados, e a política não criou um processo de retroalimentação. Caso a política pública possua ou desenvolva tais mecanismos de sustentação, a importância da constitucionalização para sua continuidade diminui.

A expectativa é que este artigo possa constituir um ponto de partida analítico tanto para o estudo do conteúdo das constituições - ainda pouco explorado pelos estudiosos da ciência política-bem como sobre o funcionamento das políticas públicas. Serão fundamentais estudos empíricos que testem e aprimorem o modelo proposto. Ademais, em linha com os argumentos aqui apresentados, cremos que há muito a fazer, especialmente no que concerne aos diferentes tipos de política pública, às diferentes áreas de política (issue areas) e à relação entre direitos constitucionalizados e políticas públicas.

(Recebido para publicação em dezembro de 2014)

(Reapresentado em setembro de 2016)

(Aprovado para publicação em dezembro de 2016) 


\section{Cláudio Gonçalves Couto e Giovanna de Moura Rocha Lima}

\section{NOTAS}

1. Na mesma linha, ver Zagrebelsky (1995) e Cambi (2007).

2. "Afirmar que as normas constitucionais têm força normativa é reconhecer que a Constituição não é apenas uma carta de intenções políticas, mas que está dotada de caráter jurídico imperativo. (...) Com efeito, o reconhecimento da força normativa da Constituição marca uma ruptura com o Direito Constitucional clássico, onde se visualizavam normas constitucionais programáticas que seriam simples declarações políticas, exortações morais ou programas futuros e, por isto, destituída de positividade ou de eficácia vinculativa" (Cambi, 2007:6-7).

3. “Nesse ambiente, a Constituição passa a ser não apenas um sistema em si-com a sua ordem, unidade e harmonia - mas também um modo de olhar e interpretar todos os demais ramos do Direito. Este fenômeno, identificado por alguns autores como filtragem constitucional, consiste em que toda a ordem jurídica deve ser lida e apreendida sob a lente da Constituição, de modo a realizar os valores nela consagrados" (Barroso, 2005:21).

4. Para críticas a esta perspectiva, ver Dimoulis (2008) e Ávila (2009).

5. Em países que não reconhecem a força normativa da constituição, existe a possibilidade de normas constitucionais programáticas não assegurarem o que veiculam enquanto não forem reguladas.

6. Para reforçar este ponto, Gustavo Zagrebelsky recorre à distinção schmittiana entre "constituição" e "lei constitucional". No Direito, entende-se por regras materialmente constitucionais (constituição) aquelas relativas aos princípios, aos direitos, às formas de governo, do Estado e de aquisição e exercício do poder, às estruturas, atribuições e competências dos órgãos do Estado e aos limites da atuação estatal. Dispositivos do texto constitucional que tratam de outros temas são considerados formalmente constitucionais (lei constitucional), já que seu conteúdo não é considerado constitucional per se. Na matriz da qual partimos neste texto, consideramos como materialmente constitucionais os chamados dispositivos veiculadores de polity: as regras relativas a definições de Estado e Nação, direitos individuais e de participação política, regras do jogo e direitos materiais orientados para o bem-estar e a igualdade. As demais normas, questões específicas e controversas destinadas a decisões concretas de governo, denominamos policy (ver Couto e Arantes 2006; Arantes e Couto 2008).

7. Poucos e raros são os países que não possuem constituições escritas; os mais notáveis são Israel, Nova Zelândia e Reino Unido. A presente discussão volta-se àqueles que as possuem.

8. Por estas razões, este texto abordará diferentes escolhas institucionais - como processo de emendamento e revisão judicial - sem se aprofundar nos possíveis motivos de sua adoção. Cremos que estes podem ser melhor explicados na análise de diferentes casos, embora reconheçamos a importância de teorizar sobre mecanismos que levam às diferentes escolhas institucionais.

9. Elkins, Ginsburg e Melton (2009) utilizam a expressão self-enforcement, que poderia ser traduzida como "autoaplicável". Para evitar confusões com o sentido dessa expressão em português, optamos por modificar o termo para self-binding, ou "autovinculante", no contexto indicado neste artigo. 


\section{Continuidade de Políticas Públicas: A Constitucionalização Importa?}

10. Seguindo Lutz (1994), consideraremos emendamento o resultado de um processo formal de alteração (adição ou subtração) no texto constitucional. Para uma crítica a essa visão, ver Levinson (2001:274).

11. Rigidez constitucional é um conceito ligado à dificuldade ou aos custos do processo de mudança formal da constituição, e usualmente foca as maiorias legislativas ou o número de vetos necessários para aprovação de uma emenda constitucional. Ver Lutz (1994); Lijphart (1999); Lorenz (2005); Rasch e Congleton (2006); Melo (2007).

12. Alguns exemplos de diferentes processos atualmente utilizados estão no relatório "Constitutional Amendment" (Constitutional Design Group, 2008).

13. "Supermaiorias em sistemas majoritários são claramente muito menos constrangedoras do que as mesmas supermaiorias em sistemas de representação proporcional" (Lijphart, 1999:220, tradução nossa).

14. “Tecnicamente, existe uma distinção entre revisão judicial, em que juízes ordinários desempenham a função de controle constitucional, e revisão de constitucionalidade, em que a função é dada para juízes especializados ou atores políticos. Este estudo usa os termos intercambiadamente" (Ginsburg, 2003:15, tradução nossa).

15. “Nos países em que essa função inexiste, o Judiciário assemelha-se a um órgão público ordinário, responsável pela importante tarefa de prestar justiça nos conflitos particulares, mas incapaz de desempenhar papel político no processo decisório normativo" (Arantes, 2007:84).

16. Há casos, considerados abaixo, em que emendas constitucionais (e, portanto, normas constitucionais) também foram consideradas inconstitucionais.

17. A escolha entre o modelo concentrado ou difuso é colocada pelo autor como uma diferença de acesso.

18. É claro que os casos de política pública que são consideradas polity quando constitucionalizadas não se encaixam neste raciocínio.

19. Para os fins de nossa discussão, o que importa é se ocorre ou não a mudança dos objetivos, e não as suas razões últimas. Peter Hall (1993:279) dá especial atenção a mudanças que implicam a alteração na hierarquia de objetivos por trás das políticas, podendo decorrer de alterações no arcabouço interpretativo de seus formuladores, ao que denomina mudança de paradigma. O exemplo da mudança da política macroeconômica seria, para o autor, um caso deste tipo. Para nós, o que importa é apenas que se trata de uma mudança profunda, isto é, de objetivos.

20. Para mais sobre esse fenômeno, ver Pierson e Hacker (2010:19).

21. Cremos que esta definição de continuidade sirva para os propósitos teóricos deste artigo. Admitimos, porém, a possibilidade de que o corte entre continuidade e descontinuidade seja feito utilizando como critério a permanência apenas dos objetivos ao longo do tempo. Esta opção pode ser mais adequada por motivos relacionados ao desenho de pesquisa ou à natureza da política - a mudança de instrumentos pode ter grande relevância em determinados casos, como, por exemplo, a mudança da provisão direta para a privatização de serviços em políticas de saúde ou educação. Cremos que tal adaptação seja importante. Ainda que implique ajuste de algumas das suposições que fazemos na próxima seção, de forma nenhuma as invalida.

22. Os argumentos utilizados aqui foram, em sua maioria, desenvolvidos tendo por objeto instituições formais. Seguindo o que faz Pierson $(2004,2006)$, adaptamos estes 


\section{Cláudio Gonçalves Couto e Giovanna de Moura Rocha Lima}

argumentos para a análise de políticas públicas, pois estas funcionam de modo análogo ao das instituições formais.

23. Foram os trabalhos de Schattschneider $(1935)$ e Lowi $(1964,1972)$ que notavelmente argumentaram que novas políticas públicas criam novos jogos políticos e que o jogo político segue as políticas públicas.

24. De fato, a discussão feita aqui supõe ação de alguns atores interessados em descontinuar a política. Caso contrário, as políticas continuariam, a não ser que sua descontinuidade fosse prevista em seu próprio desenho - como, por exemplo, em disposições constitucionais transitórias.

25. Note-se que nossa definição de constitucionalização difere da adotada pelos neoconstitucionalistas, pois o que nos importa aqui é a proteção a uma norma produzida pelo fato de ela constar do texto constitucional, ao passo que os neoconstitucionalistas trabalham com a ideia de uma constitucionalização geral das normas.

26. Especialmente em políticas controversas que sejam apontadas como inconstitucionais por seus adversários, como na recente discussão acerca da nova política de saúde norte-americana, apelidada de "Obamacare".

27. Imaginamos que um índice seja uma boa forma de agregar essas informações. A elaboração de um Índice de Proteção Constitucional não está contemplada neste trabalho, mas é uma sugestão para os trabalhos empíricos que devem dar sequência a este.

28. A distinção entre policy e polity é definida em Couto e Arantes (2006).

29. No caso brasileiro, um exemplo conhecido foi o tabelamento das taxas de juros em $12 \%$ ao ano, estabelecido no Art. 192. Como o mesmo artigo estipulava a necessidade de lei complementar para regular seus diversos dispositivos, o tabelamento dos juros jamais foi aplicado, até sua derrogação por meio da emenda constitucional no 40 , em 2003.

30. A dificuldade de emendamento ou revisão não diz respeito unicamente às regras formais de modificação do texto constitucional tais como quóruns de votação, decisão bicameral, exigência de referendos ou plebiscitos, homologação pelos estados, etc. Ela pode também ter a ver com o grau de "santificação" do texto constitucional, nos termos de Arantes e Couto (2010:559), ou seja, "caso a Constituição - para além do juízo substantivo que os atores políticos façam sobre seus conteúdos - esteja revestida de uma legitimidade tão grande que eles se abstenham de tentar modificá-la, mesmo que ela seja passível de transformação fácil" do ponto de vista procedimental, torna-se na prática difícil modificá-la. Assim, a facilidade/dificuldade de emendamento contempla tanto a rigidez constitucional quanto a capacidade mobilizadora da constituição.

31. Site da Câmara dos Deputados, acessado em 12/9/2016.

32. As oito leis atinentes à legislação eleitoral aprovadas nesse período foram: 9.100/1995, 9.430/1996, 9.504/1997, 9.840/1999, 11.300/2006, 12.034/2009, $12.891 / 2013$ e 13.165/2015. As quatro decisões do STF, fossem liminares ou finais, foram: ADI 2530/2001, ADI 3741/2006, ADI 4543/2011 e ADI 5105/2014. Disponíveis em http:/ / www.planalto.gov.br e http:/ / www.stf.jus.br. Acessadas em 12/9/2016. 


\section{REFERÊNCIAS BIBLIOGRÁFICAS}

ARANTES, Rogério B. (2007), “Judiciário e Política no Brasil”, in L. Avelar; A. O. Cintra. (orgs.), Sistema Político Brasileiro: Uma Introdução. (2a ed.). Rio de Janeiro; São Paulo, Fundação Konrad Adenauer; Editora Unesp, pp. 81-115.

ARANTES, Rogério B.; COUTO, Cláudio G. (2008), "A Constituição sem Fim", in S. Diniz; S. Praça (orgs.), Vinte Anos de Constituição. São Paulo, Paulus, pp. 31-60.

(2010), "Construção Democrática e Modelos de Constituição". DADOS - Revista de Ciências Sociais, vol. 53, no 3, pp. 545-585.

ÁVILA, Humberto. (2009), “'Neoconstitucionalismo': Entre a ‘Ciência do Direito' e o ‘Direito da Ciência'". Revista Eletrônica de Direito do Estado (REDE), Salvador, Instituto Brasileiro de Direito Público, no 17. Disponível em: http://www.direitodoestado.com.br/rede.asp

BARCELlOS, Ana Paula de. (2005), "Neoconstitucionalismo, Direitos Fundamentais e Controle das Políticas Públicas". Revista de Direito Administrativo, vol. 240, pp. 83-103.

BARROSO, Luís Roberto. (2005), “Neoconstitucionalismo e Constitucionalização do Direito (O Triunfo Tardio do Direito Constitucional no Brasil)". Revista de Direito Administrativo, vol. 240, pp.1-42.

BRASIL. (1988), Constituição da República Federativa do Brasil de 1988. Disponível em http://www.planalto.gov.br/ccivil_03/constituicao/constituicao.htm

. (2016). Lei de Responsabilidade Fiscal [recurso eletrônico]: Lei complementar n-101, de 4 de maio de 2000, e Legislação Correlata. (3a ed.). Brasília, Câmara dos Deputados, Edições Câmara.

CAMBI, Eduardo. (2007), "Neoconstitucionalismo e Neoprocessualismo". Panóptica, vol. 2, no 2, pp.1-44.

CARBONELL, Miguel. (2010), “Neoconstitucionalismo y Derechos Fundamentales en América Latina: Apuntes para una Discusión". Pensamiento Constitucional, ano XIV, no 14, pp. 11-31.

COMELLA, Victor. (2009), Constitutional Courts and Democratic Values: A European Perspective. New Haven/London, Yale University Press.

CONSTITUTIONAL DESIGN GROUP. (2008), ConstitutionMaking.org Option Reports: Constitutional Amendment. Disponível em http:// <www.constitutionmaking.org/reports.html>. Acesso em 12/4/2010.

COUTO, Cláudio G.; ABRUCIO, Fernando L. (2003). "O Segundo Governo FHC: Coalizões, Agendas e Instituições”. Tempo Social, vol. 15, no 2, pp. 269-301.

COUTO, Cláudio G.; ARANTES, Rogério B. (2006), “Constituição, Governo e Democracia no Brasil". Revista Brasileira de Ciências Sociais, vol. 21, no 61, pp. 41-62.

DIMOULIS, Dimitri. (2008), “Uma Visão Crítica do Neoconstitucionalismo”, in G. S. Leite; G. Leite, Constituição e Efetividade Constitucional. Salvador, Juspodivm, pp. 43-59.

DADOS - Revista de Ciências Sociais, Rio de Janeiro, vol. 59, n 4, 2016 


\section{Cláudio Gonçalves Couto e Giovanna de Moura Rocha Lima}

ELKINS, Zachary; GINSBURG, Tom; MELTON, James. (2009), The Endurance of National Constitutions. New York, Cambridge University Press.

ELSTER, Jon. (1988), “Introduction”, in J. Elster; R. Slagstad (eds.), Constitutionalism and Democracy. Cambridge, Cambridge University Press, pp.1-18.

. (1995), "Forces and Mechanisms in the Constitution-Making Process". Duke Law Journal, vol. 45, no 2, pp. 364-396.

GINSBURG, Tom. (2003), “Introduction: The Decline and Fall of Parliamentary Sovereignty", in Judicial Review in New Democracies: Constitutional Courts in Asian Cases. New York, Cambridge University Press, pp. 1-20.

GOMES, Sandra. (2006), “O Impacto das Regras de Organização do Processo Legislativo no Comportamento dos Parlamentares: Um Estudo de Caso da Assembleia Nacional Constituinte". DADOS - Revista de Ciências Sociais, vol. 49, no 1, pp. 193-224.

HACKER, Jacob. (2004), "Privatizing Risk without Privatizing the Welfare State: The Hidden Politics of Social Policy". The American Political Science Review, vol. 98, no 2, pp. $243-260$.

HALL, Peter. (1993), "Policy Paradigms, Social Learning, and the State: The Case of Economic Policymaking in Britain". Comparative Politics, vol. 25, no 3, pp. 275-296.

HAMMONS, Christopher W. (1999), “Was James Madison Wrong? Rethinking the American Preference for Short, Framework-Oriented Constitutions". American Political Science Review, vol. 93, no 4, pp. 837-849.

HAMMONS, Christopher W. (2001), "State Constitutional Reform: Is it Necessary?". Albany Law Review, vol. 64, pp. 1327-1354.

HARDIN, Russell. (1999), Liberalism, Constitutionalism, and Democracy. New York, Oxford University Press.

HOLMES, Stephen. (1988), "Precommitment and the Paradox of Democracy", in J. Elster; R. Slagstad (eds.), Constitutionalism and Democracy, Cambridge, Cambridge University Press, pp. 195-240.

HOROWITZ, Donald. (2002), “Constitutional Design: Proposals versus Processes”, in A. Reynolds (ed.), The Architecture of Democracy: Constitutional Design, Conflict Management, and Democracy. Oxford, Oxford University Press, pp. 15-36.

JACOBS, Alan M.; WEAVER, R. Kent. (2010), Policy Feedback and Policy Change. Trabalho apresentado na reunião anual da APSA, 16-19 de maio, Orlando.

LEVINSON, Sanford. (2001), “Designing an Amendment Process”, in J. Ferejohn; J. N. Rakove; J. Riley (eds.), Constitutional Culture and Democratic Rule. United Kingdom, Cambridge University Press, pp. 271-287.

LIJPHART, Arend. (1999), Patterns of Democracy. New Haven, Yale University Press.

LORENZ, Astrid. (2005), “How to Measure Constitutional Rigidity: Four Concepts and Two Alternatives". Journal of Theoretical Politics, vol. 17, no 3, pp. 339-361.

LOWI, Theodore. (1964), “American Business, Public Policy, Case-Studies, and Political Theory". World Politics, vol. 16, no 4, pp. 677-715.

. (1972), "Four Systems of Policy, Politics, and Choice". Public Administration Review, vol. 32, no 4, pp. 298-310. 


\section{Continuidade de Políticas Públicas: A Constitucionalização Importa?}

LUTZ, Donald. (1994), "Toward a Theory of Constitutional Amendment”. The American Political Science Review, vol. 88, no 2, pp. 355-370.

. (2006), "Constitutionalism: An Initial Overview and Introduction", in Principles of Constitutional Design. New York/Cambridge, Cambridge University Press, pp. 1-25.

MELO, Marcus A. (2007), "Hiperconstitucionalização e Qualidade da Democracia: Mitos e Realidade", in C. R. Melo; M. Sáez (orgs.), A Democracia Brasileira: Balanço e Perspectivas para o Século 21. Belo Horizonte, UFMG Editora, pp. 237-266.

NEGRETTO, Gabriel. (2008), "The Durability of Constitutions in Changing Environments: Explaining Constitutional Replacements in Latin America". Working Paper, 350, Kellogg Institute.

NUÑES LEIVA, J. Ignacio. (2012), “Constitución, Neoconstitucionalismo y Lagunas Jurídicas (Normativas y Axiológicas)”. Estudios Constitucionales, ano 10, no 2, pp. 511-532.

PATASHNIK, Eric; ZELIZER, Julian E. (2009), When Policy Does Not Remake Politics: The Limits of Policy Feedback. Trabalho apresentado na reunião anual da APSA, 3-6 de setembro, Toronto.

PIERSON, Paul. (2000), "The Limits of Design: Explaining Institutional Origins and Change. Governance: An international Journal of Policy and Administration, vol. 13, no 4, pp. 475-499.

. (2004), Politics in Time: History, Institutions, and Social Analysis. Princeton, Princeton University Press.

. (2006), "Public Policies as Institutions", in I. Shapiro; S. Skowronek; D. Galvin (eds.), Rethinking Political Institutions. New York, New York University Press, pp. 114-133.

; HACKER, Jacob. (2010), Drift and Democracy: The Neglected Politics of Policy Inaction. Trabalho apresentado na reunião anual da APSA, 16-19 de maio, Orlando.

RASCH, Bjorn Erik; CONGLETON, Roger D. (2006), "Amendment Procedures and Constitutional Stability", in R. D. Congleton; B. Swedenborg (eds.), Democratic Constitutional Design and Public Policy. Cambridge, MIT Press, pp. 319-342.

SCHATTSCHNEIDER, Elmer E. (1935), Politics, Pressures and the Tariff. New York, PrenticeHall.

THELEN, Kathleen. (1999), "Historical Institutionalism". Comparative Politics. Annual Review of Political Science, vol. 2, pp. 369-404.

(2003), “How Institutions Evolve: Insights from Comparative Historical Analysis", in J. Mahoney; D. Rueschemeyer (eds.), Comparative Historical Analysis in the Social Sciences. Cambridge, Cambridge University Press, pp. 208-240.

ZAGREBELSKY, Gustavo. (1995), El Derecho Dúctil: Ley, Derechos, Justicia. Madrid, Editorial Trotta.

DADOS - Revista de Ciências Sociais, Rio de Janeiro, vol. 59, n- 4, 2016 


\section{RESUMO}

\section{Continuidade de Políticas Públicas: A Constitucionalização Importa?}

De que forma a constitucionalização de políticas públicas, ou seja, a transformação de normas que especificam ou estruturam políticas públicas em letra constitucional, afeta sua continuidade? Dialogando com as literaturas sobre constitucionalismo e políticas públicas, propomos um modelo de análise em que a explicação da continuidade das políticas resulta de seu status constitucional e suas fontes de resiliência. Políticas públicas com alto grau de resiliência terão continuidade, independentemente de seu status constitucional; já quando a política apresenta baixo grau de resiliência, o status constitucional ganha importância como definidor de sua trajetória, pois um elevado status constitucional garante, em princípio, sua continuidade. Por fim, um baixo status constitucional de uma política pública favorece sua descontinuidade quando o grau de resiliência é baixo demais para que, por si só, seja contribua para mantê-la. Além de propor um modelo analítico, o artigo analisa, como exemplos, quatro casos em que o modelo se aplica.

Palavras-Chave: Constituição; políticas públicas; mudança constitucional; continuidade de políticas públicas; processo decisório

\section{ABSTRACT \\ The Continuity of Public Policies: Does Constitutionalization Matter?}

The following article asks how the constitutionalization of public policies affects the continuity of such policies, with "constitutionalization" understood as the transformation of norms structuring public policies into constitutional text. By means of a dialogue with literature published on constitutionalism and public policies, we propose a model of analysis in which the continuity of policies results from their constitutional status and sources of resilience. Public policies with a high degree of resilience will remain in effect regardless of their constitutional status; while the fate of policies with low degrees of resilience is defined by their constitutional status, since a high constitutional status should guarantee continuity. Public policies with a low constitutional status will see their continuity seriously compromised when their degree of resilience is too low to ensure such continuity in itself. In addition to proposing an analytical model, the article analyzes four cases in which the model applies.

Key words: Constitution; public policy; constitutional change; continuity of public policies; decision-making process 


\author{
RÉSUMÉ \\ Continuité des Politiques Publiques: La Constitutionnalisation \\ Importe-t-elle?
}

De quelle manière la constitutionnalisation des politiques publiques, à savoir l'inscription des normes qui les spécifient ou les structurent dans le texte constitutionnel, affecte-t-elle leur continuité? En dialoguant avec les littératures relatives au constitutionnalisme et aux politiques publiques, nous proposons ici un modèle analytique où l'explication de la continuité des politiques résulte de leur statut constitutionnel et de leurs sources de résilience. Les politiques publiques dotée d'un haut degré de résilience voient leur continuité assurée, indépendamment de leur statut constitutionnel, tandis que pour les politiques peu résilientes, leur trajectoire dépend amplement de leur statut constitutionnel, étant entendu qu'un statut constitutionnel conséquent garantit en principe leur pérennité. Pour finir, un statut constitutionnel de moindre importance favorise la discontinuité d'une politique publique, principalement si le degré de résilience est trop faible pour contribuer à lui-seul à son maintien. Outre le modèle analytique qu'il propose, cet article analyse à titre d'exemple quatre cas où le modèle peut s'appliquer.

Mots-clés: Constitution; politiques publiques; changements constitutionnels; continuité des politiques publiques; processus de prise de décision

\title{
RESUMEN
}

\section{Continuidad de Políticas Públicas: ¿La Constitucionalización Importa?}

¿De qué manera la constitucionalización de políticas públicas, es decir, la transformación de normas que especifican o estructuran políticas públicas en letra constitucional, afecta su continuidad? En diálogo con las literaturas sobre constitucionalismo y políticas públicas, proponemos un modelo de análisis en que la explicación de la continuidad de las políticas resulta de su status constitucional y sus fuentes de resiliencia. Las políticas públicas con alto grado de resiliencia tendrán continuidad, independientemente de su status constitucional; a su vez, cuando la política presenta bajo grado de resiliencia, el status constitucional adquiere importancia como definidor de su trayectoria, pues un elevado status constitucional garantiza, en principio, su continuidad. Por fin, un bajo status constitucional de una política pública favorece su discontinuidad cuando el grado de resiliencia es demasiado bajo como para, por sí solo, contribuir a mantenerla. Además de proponer un modelo analítico, el artículo analiza como ejemplos cuatro casos en que se aplica el modelo.

Palabras clave: Constitución; políticas públicas; cambio constitucional; continuidad de políticas públicas; proceso decisorio 